\title{
Cobalt Ferrite Nanocrystallites for Sustainable Hydrogen Production Application
}

\author{
Rajendra S. Gaikwad, ${ }^{1}$ Sang-Youn Chae, ${ }^{1}$ Rajaram S. Mane, ${ }^{1,2}$ \\ Sung-Hwan Han, ${ }^{3}$ and Oh-Shim Joo ${ }^{1}$ \\ ${ }^{1}$ Clean Energy Research Centre, Korea Institute of Science and Technology, Seoul 130-650, Republic of Korea \\ ${ }^{2}$ School of Physical Sciences, Swami Ramanand Teerth Marathwada University, Nanded 431 606, India \\ ${ }^{3}$ Inorganic Nanomaterials Laboratory, Department of Chemistry, Hanyang University, Seoul 133-791, Republic of Korea
}

Correspondence should be addressed to Oh-Shim Joo, joocat@kist.re.kr

Received 22 January 2011; Accepted 26 February 2011

Academic Editor: Bengi Uslu

Copyright ( 2011 Rajendra S. Gaikwad et al. This is an open access article distributed under the Creative Commons Attribution License, which permits unrestricted use, distribution, and reproduction in any medium, provided the original work is properly cited.

Cobalt ferrite, $\mathrm{CoFe}_{2} \mathrm{O}_{4}$, nanocrystalline films were deposited using electrostatic spray method and explored in sustainable hydrogen production application. Reflection planes in X-ray diffraction pattern confirm $\mathrm{CoFe}_{2} \mathrm{O}_{4}$ phase. The surface scanning microscopy photoimages reveal an agglomeration of closely-packed $\mathrm{CoFe}_{2} \mathrm{O}_{4}$ nanoflakes. Concentrated solar-panel, a two-step water splitting process, measurement technique was preferred for measuring the hydrogen generation rate. For about $5 \mathrm{hr}$ sustainable, $440 \mathrm{~mL} / \mathrm{hr}$, hydrogen production activity was achieved, confirming the efficient use of cobalt ferrite nanocrystallites film in hydrogen production application.

\section{Introduction}

Special magnetic and electrical properties, high chemical, and mechanical hardness [1], in modern information technology, have made ferrite films significantly important while designing the electromagnetic devices including the memories [2], sensors [3], and microwaves [4]. In particular, spinel-type ferrites such as $\mathrm{MFe}_{2} \mathrm{O}_{4}$ where $\mathrm{M}=\mathrm{Co}$, Ni are among the most important magnetic materials which have been previously preferred over the past half century $[5,6]$. On account of large magnetocrystalline anisotropy, high coercivity, moderate saturation magnetization, large magnetostrictive coefficient, chemical stability, and mechanical hardness, which generally are helpful for magnetic recording devices, magneto-optical recording, and electronic devices, cobalt ferrites are nowadays highly in demand. Currently, the well-known established techniques used for fabricating the ferrite films include pulsed laser deposition, rf-magnetron sputtering, electron beam evaporation, metal organic chemical vapour deposition, and molecular beam epitaxy [7-10]. Most of these techniques involve a two step process. In the first step, the desired ferrite material is synthesized in the bulk form using conventional method, and in the second step, synthesized bulk material is used as a target for irradiation by high power laser, ion/electron beam, or rf source. The resultant plume is then captured on a cold substrate. These techniques require a high power source and/or an ultrahigh vacuum system, making them extremely capital and energy intensive. These techniques are also not suited to obtain conformal coatings on curved substrates. Furthermore, these techniques are inapplicable when the target material is maintained at low-temperatures, as an irradiation would lead to instantaneous decomposition of the target material [11]. There is, therefore, a need to develop simple and inexpensive wet chemical approach for synthesizing ferrite nanostructures on variety of substrates at ambient temperature. Different chemical methods such as ferrite plating [12, 13], sol-gel [14], spin spray ferrite plating [15], and modified ferrite plating [16], spray pyrolysis [17], and the thin liquid film method [18] have been documented in the literature for depositing ferrite nanostructures in the films form. The multicomponent, nanocrystalline, active redox water splitting cobalt ferrite films can be fabricated using electrostatic spray pyrolysis (ESP) electronic method. 
Cobalt ferrite films, synthesized using this method, could offer several advantages, for example, synthesis at low temperatures, especially, below $150^{\circ} \mathrm{C}$ that would be environmentally benign for hydrogen production application [19]. Secondly, available conventional methods such as electrodeposition or normal spray pyrolysis are facing serious large area uniform deposition problem that can be easily solved in ESP method as ESP is a simple chemical synthesis technique in which the high potential field is applied between the substrate and spray nozzle for acceleration.

Chemical synthesis of cobalt ferrite nanocrystalline films using $\left.\mathrm{Co}\left(\mathrm{CH}_{3} \mathrm{COO}\right)_{2}\right) \cdot 2 \mathrm{H}_{2} \mathrm{O}$ and $\mathrm{Fe}\left(\mathrm{NO}_{3}\right)_{3} \cdot 9 \mathrm{H}_{2} \mathrm{O}$ is quite known [20, 21]; however, its direct implication in hydrogen production application is quite unknown. Therefore, in the present paper, we report the synthesis of smooth and uniform cobalt ferrite nanocrystallites films using ESP method. Various parameters including the substrate temperature, carrier gas flow rate, solution flow rate, droplet size, nozzleto-substrate distance, were optimized for acquiring adherent and high quality films. The X-ray diffraction (XRD) analysis, X-ray photoelectron spectroscopy (XPS), the scanning electron microscopy (SEM), and atomic force microscopy (AFM) techniques were preferred for the structural elucidation and surface morphological evolution confirmation. Cobalt ferrite films deposited onto a glass substrate were employed for an optical and surface hydrophilicity studies using Uv-Vis spectrophotometry and water contact angle techniques, respectively. For an optical absorption measurement, deposited onto glass substrate, Cranx $100 \mathrm{UV}$-Vis spectrophotometer was preferred. Finally, cobalt ferrite films deposited onto stainless substrate of about $9 \times 9 \mathrm{~cm}^{2}$ surface area were utilized in hydrogen production activity. During old fashion of hydrogen production, photoelectrochemical (PEC) cell system was used in water splitting process which mainly preferred semiconductor materials photoelectrode, for generating electron-hole pairs [22].

In the relatively new system, silicon solar cell and electrolytic cell are used as active components wherein, for water electrolysis, silicon solar cell provides biasing current to the cathode-anode electrode assembly in an electrolytic cell. The water electrolysis in this system is expected through three steps. The incident solar energy generates electron-hole pairs due to silicon solar cell, in a first step. In a second step, these electron-hole pairs flow through the cathode-anode electrolyte assembly followed by water electrolysis in a third step,

$$
\text { Energy }(\text { solar })+\text { Si solar cell } \longrightarrow 4 \mathrm{e}^{-}+4 \mathrm{~h}^{+}
$$

at cathode

$$
4 \mathrm{H}_{2} \mathrm{O}+4 \mathrm{e}^{-} \longrightarrow 2 \mathrm{H}_{2}+4 \mathrm{OH}^{-}+4 \mathrm{~h}^{+}
$$

and at anode

$$
4 \mathrm{OH}^{-}+4 \mathrm{~h}^{+} \longrightarrow \mathrm{O}_{2}+2 \mathrm{H}_{2} \mathrm{O}+4 \mathrm{e}^{-} .
$$

\section{Experimental Details}

The ESP technique feasibly facilitates the formation of cobaltite films onto commonly available and inexpensive glass and stainless steel substrates. These substrates were well cleaned (glass: deionized water, isopropanol, acetone in ultrasonic bath; stainless steel: a zero polishing paper and then ultrasonication) prior to deposition process. For the cobalt ferrite deposition, the aqueous solutions of analytical reagent grade (with $99.99 \%$ purity) cobalt acetate dehydrate $\left(\mathrm{Co}\left(\mathrm{CH}_{3} \mathrm{COO}\right)_{2} \cdot 2 \mathrm{H}_{2} \mathrm{O}\right)$, and iron nitrate nanodehydrate $\left(\mathrm{Fe}\left(\mathrm{NO}_{3}\right)_{3} \cdot 9 \mathrm{H}_{2} \mathrm{O}\right)$ were mixed in ethanol and water mixture of $3: 1$ ratio. Each of the precursor concentration taken in $1: 1$ volume ratio was $0.2 \mathrm{M}$. The spraying operation was carried out under an electrostatic potential of $14 \mathrm{kV}$, at a steady temperature of $150^{\circ} \mathrm{C}$ by maintaining the substrate-to-spray nozzle distance of $18 \mathrm{~cm}$ with spray rate of $15 \mu \mathrm{L} / \mathrm{min}$. After deposition, the films were annealed at $550^{\circ} \mathrm{C}$ for $2 \mathrm{~h}$ for obtaining cobalt ferrite phase and then used for the structural, morphological, and optical studies and hydrogen production application, respectively. Thickness, measured from the depth profilometer, was close to $100 \mathrm{~nm}$. The X-ray diffractometer (Rigaku, RINT/PMAX 2500) with $\mathrm{Cu}-\mathrm{K} \alpha$ radiation wavelength of $1.5406 \AA$ was used for the structural identification. The $\mathrm{X}$-ray source was operated at $40 \mathrm{kV}$ and $100 \mathrm{~mA}$, with a drive axis in $2 \theta$ for a scan range from 20 to $80^{\circ}$. Surface morphology and surface topography and average roughness were confirmed from JEOL-JSM 5410 SEM and AFM photoimages, respectively. The sessile drop method was used to measure the contact angle by dropping a microlevel water droplet using fine syringe. The optical absorption measurement of cobaltite film, deposited onto glass substrate, was performed by using Cranx $100 \mathrm{UV}$-Vis spectrophotometer. The metal contents in cobalt ferrite films were determined by XPS using a Varian FT220s. For hydrogen production measurement, an electrolyser was fabricated with two electrodes (for oxidation and reduction reaction of $\mathrm{H}_{2} \mathrm{O}$ ). Electrolyte was $1 \mathrm{M} \mathrm{NaOH}$, and $\mathrm{Pt}$ counter electrode was for $\mathrm{H}_{2}$ evolution, and cobalt ferrite film was used for $\mathrm{H}_{2} \mathrm{O}$ oxidation. The energy for water splitting can be gained from the photoelectrode located outside of the electrolyser. The areas of photoelectrode and active electrodes were $12.5 \times 12.5$ and $9 \times 9 \mathrm{~cm}^{2}$, respectively. The light intensity was controlled to $100 \mathrm{~mW} / \mathrm{cm}^{2}$ using xenon lamp of $1.5 \mathrm{~kW}$.

\section{Results and Discussion}

The XRD spectrum of cobalt ferrite film deposited onto glass substrates after annealing at $550^{\circ} \mathrm{C}$ is shown in Figure $1(\mathrm{a})$. The XRD spectrum consists of several low intensity peaks. Structure of cobalt ferrite was confirmed after correlating observed XRD peaks to that found in standard JCPDF data card (22-1086). Identical peaks, similar to reported elsewhere [20], were indexed to (220), (311), (400), and (440) diffraction planes. The peak intensity of (311) was relatively higher than others confirming the presence of single cobalt ferrite phase instead of mixed $\mathrm{CoO}$ and $\mathrm{Fe}_{2} \mathrm{O}_{3}$ phases. This higher intensity of (311) plane can be attributed to an annealing effect that boosts the crystallinity and specific orientation of crystallites. Using Scherrer's formula, crystallite size of about $50 \mathrm{~nm}$ was calculated. The SEM image 


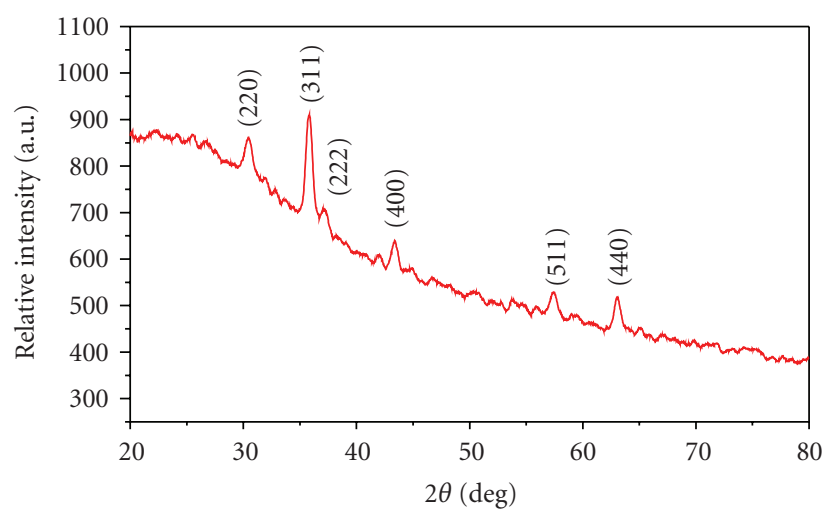

(a)

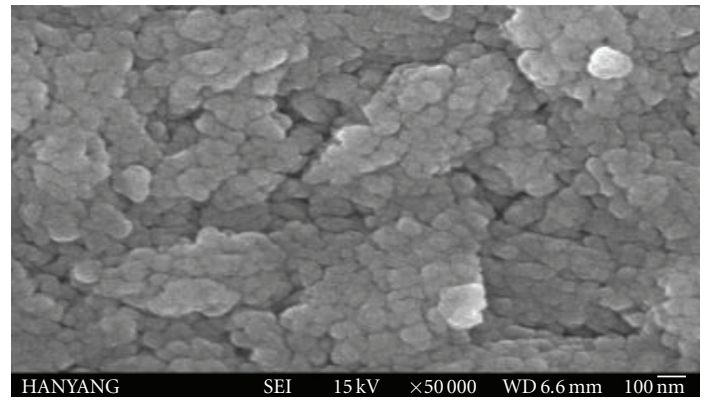

(b)

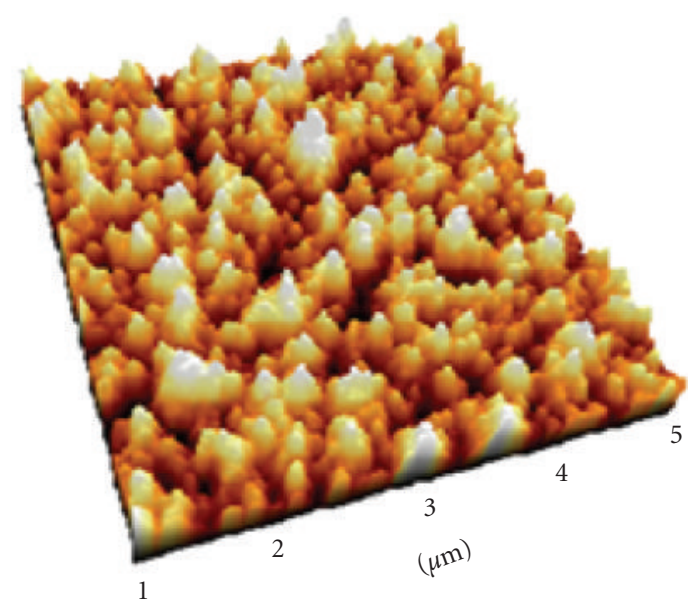

(c)

FIGURE 1: (a) Normalized XRD pattern, (b) SEM, and (c) 3D AFM image confirming the structural identification with spherical crystallites evolution of cobalt ferrite.

of cobalt ferrite film is presented in Figure 1(b). Within the scanned surface area, aggregated-type uniform coverage of cobalt ferrite nanoflakes was obtained which was free from the surface cracks or voids. It was found that these nanoflakes were made up of several oval-type elongated crystallites separated by fine and sharp grain boundaries. Each of these crystallites was $60-80 \mathrm{~nm}$ in width. However, due to their interpenetrating behaviour, it was difficult for us to measure exact individuals height. Similar type of morphology was also reported by others $[21,23]$. We expect enhanced redox reactions, due to the large surface area of these nanoparticles, can be advantageous in hydrogen production activity application. The 3D surface topography image, scanned using noncontact mode of AFM, is presented in Figure 1(c). From 3D AFM image oval-type grain texture, which was actually missing in SEM image, was confirmed.

Figure 2(a) shows the contact angle measurement photoimage recorded with CCD camera. Surface wettability, an important parameter that enables to know the surface interaction of the metal oxide with given electrolyte, was important measurement during this study. The surface of cobalt ferrite was hydrophilic as water contact angle was less than $90^{\circ}$. Water-droplet was spread equally in all directions instead of forming hilly-like dome once water droplet fixed on it [24]. In the present case, cobalt ferrite film showed hydrophilic surface with $41( \pm 2)^{\circ}$ contact angle measurement. Hydrophilic cobalt ferrite could be useful for increasing the redox reactions due to relatively strong interfacial contact between the nanoparticles electrode and electrolyte [25]. The optical absorbance spectrum as a function of the photon energy in the wavelength range of $350-800 \mathrm{~nm}$ for cobalt ferrite film deposited onto glass substrate is shown in Figure 2(b). The band gap energy was estimated by using Tauc relation [26]. The film exhibited a strong band edge around $400 \mathrm{~nm}$.

The overall chemical stoichiometry of cobalt ferrite in film was obtained from the XPS analysis. In the XPS analysis, the samples are generally exposed to the monochromic Xradiation and the properties of the inner shell electrons are probed. Figures 3(a), 3(b), and 3(c) present the XPS spectra of synthesized cobalt ferrite film for Co $2 \mathrm{p}, \mathrm{Fe} 2 \mathrm{p}$ and $\mathrm{O}$ 1s core levels. The film was composed of $\mathrm{Co}, \mathrm{Fe}$, and $\mathrm{O}$ with corresponding binding energies of 779.18 (Co 2p3/2), 794.60 (Co 2p1/2), 710.40 (Fe 2p3/2), 723.96 (Fe 2p1/2), and $529.61 \mathrm{eV}(\mathrm{O} 1 \mathrm{~s})$, respectively, and the values presented here belong to $\mathrm{Co}^{2+}, \mathrm{Fe}^{3+}$, and $\mathrm{O}^{2-}$. The analysis of the Co $2 \mathrm{p}$, $\mathrm{Fe} 2 \mathrm{p}$, and $\mathrm{O}$ 1s peaks offered $\mathrm{Co}: \mathrm{Fe}$ and $\mathrm{Fe}: \mathrm{O}$ atomic ratios close to $1: 2$ and $1: 2$, respectively, as expected for 


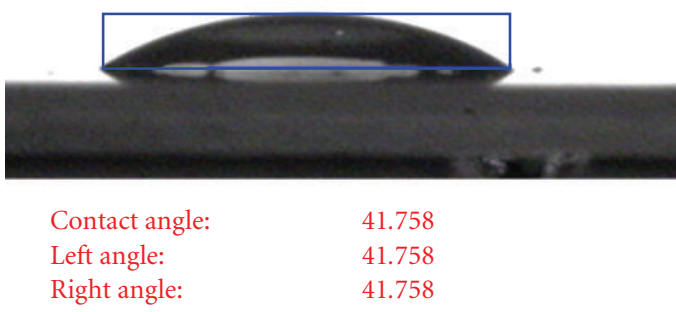

(a)

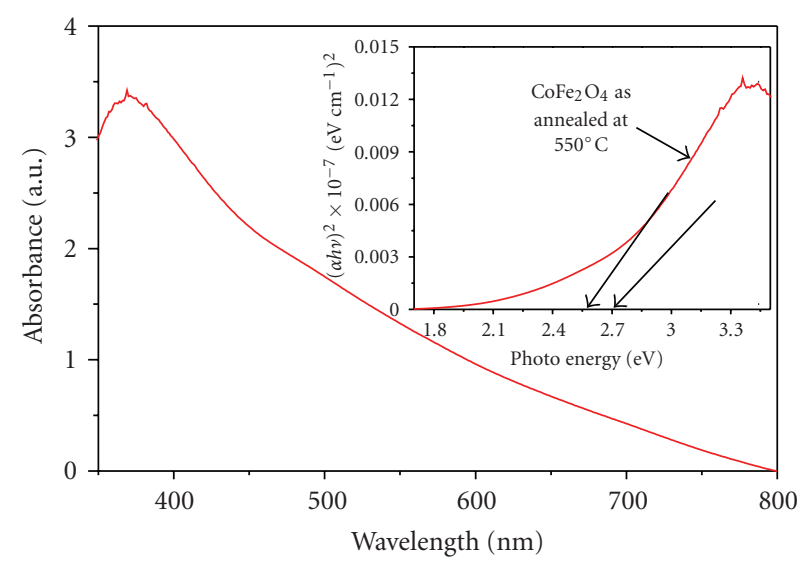

(b)

Figure 2: (a) Measurement of water contact angle, (b) Uv-Vis spectrum, and then corresponding direct band gap (inset, free arrow indicates the bulk band gap energy).

the stoichiometric composition of cobalt ferrite. The XPS measurement results were consistent to XRD observations, confirming the formation of single phase cobalt ferrite rather than mixed phases of $\mathrm{CoO}$ and $\mathrm{Fe}_{2} \mathrm{O}_{3}$. These observations suggest that annealing step played a key role during the process growth of cobalt ferrite nanoflakes. The nucleus of cobalt ferrite could be created by Co ions with the $\mathrm{Fe}^{3+}$ and $\mathrm{O}^{2-}$ on the surface of $\mathrm{Fe}_{2} \mathrm{O}_{4}$ as the $\mathrm{Fe}^{2+}$ could be easily interchanged into the $\mathrm{Fe}_{2} \mathrm{O}_{4}$ lattice by only electron transfer, $\mathrm{Fe}^{3+}$ might gather near the cobalt ferrite nucleus and became part of the ferrite lattice [27]. This could results the formation of $\mathrm{Fe}^{2+}$ rich phase left in the $\mathrm{Fe}_{2} \mathrm{O}_{4}$ among the reactions of the $\mathrm{H}_{2} \mathrm{O} / \mathrm{CoFe}_{2} \mathrm{O}_{4}$ system. To satisfy electronic neutrality, this $\mathrm{Fe}^{2+}$ rich phase could hold few $\mathrm{O}^{2-}$, so called as a cation-excess magnetite.

The cation-excess magnetite has the ability for sufficient water splitting in which some $\mathrm{Fe}^{2+}$ get oxidized to $\mathrm{Fe}^{3+}$ for $\mathrm{H}_{2} \mathrm{O} / \mathrm{CoFe}_{2} \mathrm{O}_{4}$ reaction operation. The production of pure hydrogen is based on splitting and regeneration rates. In general, the regeneration rate is temperature dependent. The most advantageous way to get such high temperature is exploitation of the photon energy of the sun which reduces the environmental utilization of polluting gases that does not cause immense and impact on the energetic and economics $[3,28]$. The water-splitting process can produce $\mathrm{H}_{2}$ gas, which is a promising solar fuel, and has the advantages that $\mathrm{H}_{2}$ and $\mathrm{O}_{2}$ gases can be separately recovered due to the two separated steps of the $\mathrm{H}_{2}$ generation step and the $\mathrm{O}_{2}$ releasing step. The two-step water-splitting processes that uses metal oxides, MOred/MOox, as a redox pair utilizing the concentrated solar heat, can be presented using the following oxygen and hydrogen production steps:

$\mathrm{O}_{2}$ generation

$$
x \text { MOox }+ \text { solar energy } \longrightarrow x \text { MOred }+\frac{1}{2} \mathrm{O}_{2}
$$

$\mathrm{H}_{2}$ generation

$$
x \text { MOred }+\mathrm{H}_{2} \mathrm{O}(\mathrm{g}) \longrightarrow x \mathrm{MOox}+\mathrm{H}_{2},
$$

where MOred and MOox denote the reduced and oxidized states, respectively. The net reaction is

$$
\mathrm{H}_{2} \mathrm{O}+\text { solar energy } \longrightarrow \mathrm{H}_{2}+\frac{1}{2} \mathrm{O}_{2} \text {. }
$$

Iron oxides have a higher possibility for utilization in the two-step water-splitting system, as they are oxides with different oxidation states [29]. The practical operating temperature for the $\mathrm{O}_{2}$ releasing step of the cobalt ferrite was quite unknown. Lowering the operating temperature for the $\mathrm{O}_{2}$ generation step was an important step for the practical production of solar hydrogen. While the gas phase $\left(\mathrm{Co}, \mathrm{O}_{2}\right)$ formation from $\mathrm{CoO}$ by the solar thermochemical process has been extensively studied $[30,31]$, but that from the $\mathrm{CoFe}_{2} \mathrm{O}_{4}$ phase has not yet been reported. In Figure 3(d), the amount of hydrogen production rate $(\mathrm{L} / \mathrm{hr})$ with time showed the stability of the system wherein the water-splitting conversion was totally depending upon product characteristics. Cobalt ferrite film synthesized on stainless steel substrate using electrostatic spray pyrolysis showed comparable watersplitting activity when compared with zinc ferrite films $(450 \mathrm{~mL} / \mathrm{hr})$ [32]. Water splitting rate, that is, hydrogen production rate was almost the same during the total time span. It is noteworthy that there was no chemical dissociation or degradation of photoanode, cobalt ferrite electrode during the oxidation-reduction process, which, in fact, was advantageous in long-run hydrogen production application due to good chemical stability of cobalt ferrite electrode.

\section{Conclusions}

In summary, the present work deals with an electrostatical synthesis of cobalt ferrite films and its sustainable hydrogen production application. Cobalt ferrite films, deposited onto both conducting steel and glass substrates, were uniform and free from the pinholes or cracks. Films obtained onto glass substrates were examined for structural, morphological, optical, and surface wettability characteristics whereas those 


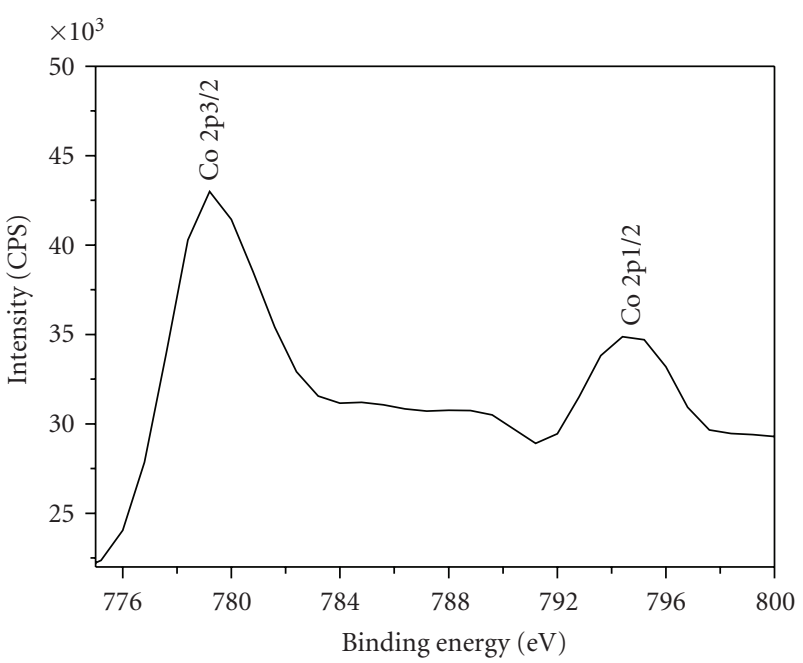

(a)

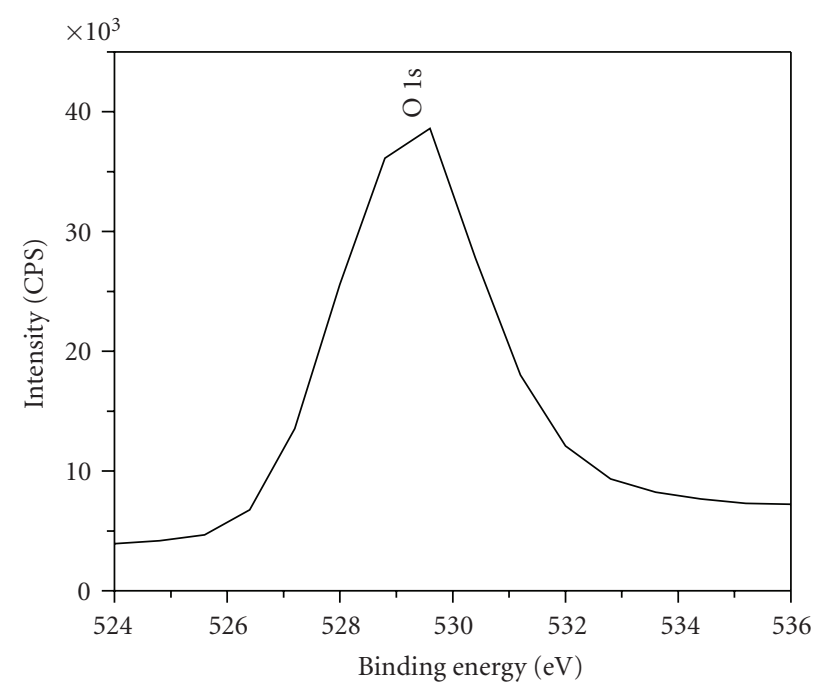

(c)

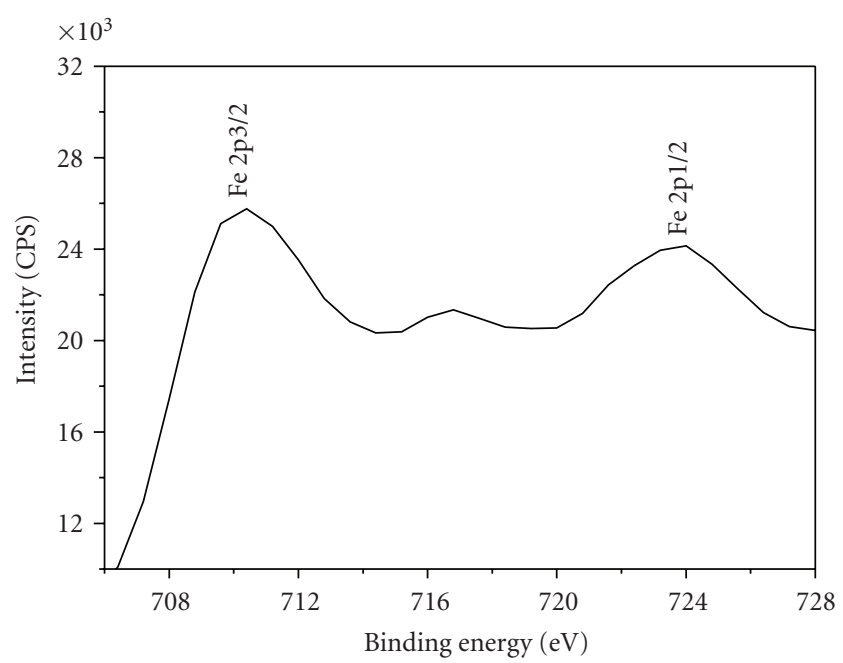

(b)

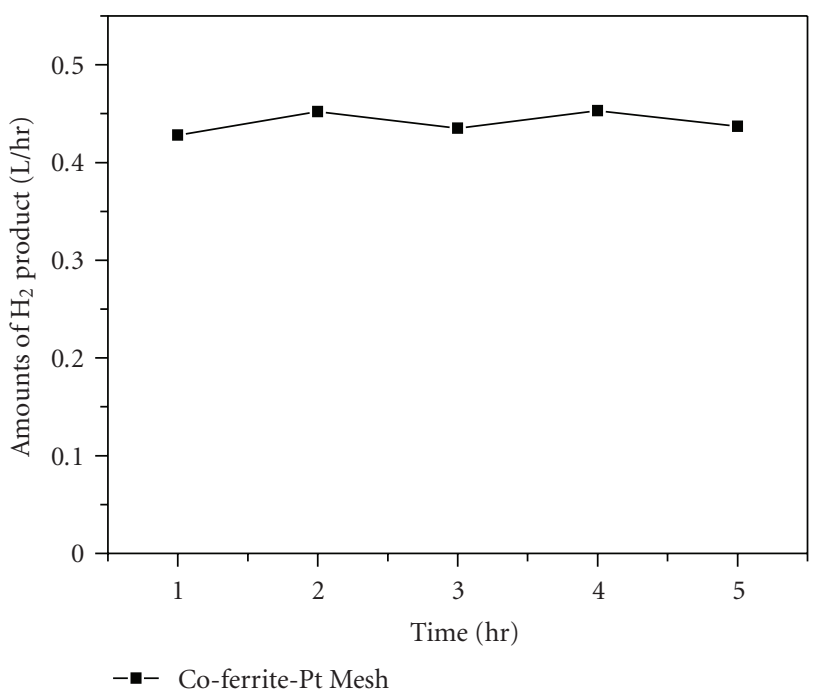

(d)

Figure 3: The XPS spectra of (a) Co 2p, (b) Fe 2p, (c) O 1s core levels, and (d) quantitative measurement of hydrogen production rate using cobaltite films.

onto stainless steel were used for hydrogen production activity application. The XRD and XPS measurements proved the formation of single phase of $\mathrm{CoFe}_{2} \mathrm{O}_{4}$ instead of mixed phased. The SEM image showed agglomeration of closely packed nanoflakes with a direct band gap energy of $2.57 \mathrm{eV}$ and water contact angle of $41( \pm 2)^{\circ}$. Finally, about $440 \mathrm{~mL} / \mathrm{hr}$ hydrogen generation activity for more than $5 \mathrm{hr}$ was obtained.

\section{Acknowledgment}

The authors appreciate the financial support from the Hydrogen Energy R \& D Centre, one of the 21st century frontiers R \& D program funded by Ministry of Science and Technology of Korea.

\section{References}

[1] Z. Wu, M. Okuya, and S. Kaneko, "Spray pyrolysis deposition of zinc ferrite films from metal nitrates solutions," Thin Solid Films, vol. 385, no. 1-2, pp. 109-114, 2001.

[2] H. Kaneko, N. Gokon, N. Hasegawa, and Y. Tamaura, "Solar thermochemical process for hydrogen production using ferrites," Energy, vol. 30, no. 11-12, pp. 2171-2178, 2005.

[3] S. Lorentzou, C. C. Agrafiotis, and A. G. Konstandopoulos, "Aerosol spray pyrolysis synthesis of water-splitting ferrites for solar hydrogen production," Granular Matter, vol. 10, no. 2, pp. 113-122, 2008.

[4] C. Agrafiotis, M. Roeb, A. G. Konstandopoulos et al., "Solar water splitting for hydrogen production with monolithic reactors," Solar Energy, vol. 79, no. 4, pp. 409-421, 2005. 
[5] M. Roeb, C. Sattler, R. Klüser et al., "Solar hydrogen production by a two-step cycle based on mixed iron oxides," Journal of Solar Energy Engineering, vol. 128, no. 2, pp. 125-133, 2006.

[6] S. Zhang, J. Liu, Y. Han, B. Chen, and X. Li, "Formation mechanisms of $\mathrm{SrTiO}_{3}$ nanoparticles under hydrothermal conditions," Materials Science and Engineering B, vol. 110, no. 1, pp. 11-17, 2004.

[7] C. Inui, Y. Tsuge, H. Kura, S. Fujihara, S. Shiratori, and T. Sato, "Preparation of one-dimensional photonic crystals by sol-gel process for magneto-optical materials," Thin Solid Films, vol. 516, no. 9, pp. 2454-2459, 2008.

[8] Y. C. Wang, J. Ding, J. B. Yi, B. H. Liu, T. Yu, and Z. X. Shen, "High-coercivity Co-ferrite thin films on (100)- $\mathrm{SiO}_{2}$ substrate," Applied Physics Letters, vol. 84, no. 14, pp. 25962598, 2004.

[9] P. D. Thang, G. Rijnders, and D. H. A. Blank, "Stress-induced magnetic anisotropy of $\mathrm{CoFe}_{2} \mathrm{O}_{4}$ thin films using pulsed laser deposition," Journal of Magnetism and Magnetic Materials, vol. 310, no. 2, pp. 2621-2623, 2007.

[10] C. Araújo, B. G. Almeida, M. Aguiar, and J. A. Mendes, "Structural and magnetic properties of $\mathrm{CoFe}_{2} \mathrm{O}_{4}$ thin films deposited by laser ablation on Si (001) substrates," Vacuum, vol. 82, no. 12, pp. 1437-1440, 2008.

[11] M. Lie, K. B. Klepper, O. Nilsen, H. Fjellvåg, and A. Kjekshus, "Growth of iron cobalt oxides by atomic layer deposition," Dalton Transactions, no. 2, pp. 253-259, 2008.

[12] J. X. Wang, H. Inada, L. Wu et al., "Oxygen reduction on well-defined core-shell nanocatalysts: particle size, facet, and Pt shell thickness effects," Journal of the American Chemical Society, vol. 131, no. 47, pp. 17299-17302, 2009.

[13] N. Gupta, A. Verma, S. C. Kashyap, and D. C. Dube, "Microstructural, dielectric and magnetic behavior of spindeposited nanocrystalline nickel-zinc ferrite thin films for microwave applications," Journal of Magnetism and Magnetic Materials, vol. 308, no. 1, pp. 137-142, 2007.

[14] A. Kleiman-Shwarsctein, M. N. Huda, A. Walsh et al., "Electrodeposited aluminum-doped $\alpha-\mathrm{Fe}_{2} \mathrm{O}_{3}$ photoelectrodes: experiment and theory," Chemistry of Materials, vol. 22, no. 2, pp. 510-517, 2010.

[15] P. S. Anil Kumar, J. J. Shrotri, S. D. Kulkarni, C. E. Deshpande, and S. K. Date, "Low temperature synthesis of $\mathrm{Ni}_{0.8} \mathrm{Zn}_{0.2} \mathrm{Fe}_{2} \mathrm{O}_{4}$ powder and its characterization," Materials Letters, vol. 27, no. 6, pp. 293-296, 1996.

[16] J. G. Barbosa, M. R. Pereira, J. A. Mendes, M. P. Proença, J. P. Araújo, and B. G. Almeida, "Cobalt ferrite thin films deposited by electrophoresis on p-doped Si substrates," Journal of Physics: Conference Series, vol. 200, Article ID 072009, 2010.

[17] Z. Gu, XU. Xiang, G. Fan, and F. Li, "Facile synthesis and characterization of cobalt ferrite nanocrystals via a simple reduction-oxidation route," Journal of Physical Chemistry C, vol. 112, no. 47, pp. 18459-18466, 2008.

[18] M. Endo, H. Nakane, and H. Adachi, "Field emission from transition metal nitride," Applied Surface Science, vol. 100-101, pp. 378-382, 1996.

[19] R. J. McQueeney, M. Yethiraj, S. Chang et al., "Zener double exchange from local valence fluctuations in magnetite," Physical Review Letters, vol. 99, no. 24, Article ID 246401, 2007.

[20] F. Cheng, Z. Peng, Z. Xu, C. Liao, and C. Yan, "The sol-gel preparation and AFM study of spinel $\mathrm{CoFe}_{2} \mathrm{O}_{4}$ thin film," Thin Solid Films, vol. 339, no. 1-2, pp. 109-113, 1999.

[21] M. Aronniemi, J. Lahtinen, and P. Hautojärvi, "Characterization of iron oxide thin films," Surface and Interface Analysis, vol. 36, no. 8, pp. 1004-1006, 2004.
[22] T. Bak, J. Nowotny, M. Rekas, and C. C. Sorrell, "Photoelectrochemical hydrogen generation from water using solar energy. Materials-related aspects," International Journal of Hydrogen Energy, vol. 27, no. 10, pp. 991-1022, 2002.

[23] A. G. King and S. T. Keswani, "Colloid mills: theory and experiment," Journal of the American Ceramic Society, vol. 77, no. 3, pp. 769-777, 1994.

[24] Z. Zhang, H. Chen, J. Zhong, G. Saraf, and Y. Lu, "Fast and reversible wettability transitions on $\mathrm{ZnO}$ nanostructures," Journal of Electronic Materials, vol. 36, no. 8, pp. 895-899, 2007.

[25] H. Aoki, H. Kaneko, N. Hasegawa, H. Ishihara, A. Suzuki, and Y. Tamaura, "The $\mathrm{ZnFe}_{2} \mathrm{O}_{4} /\left(\mathrm{ZnO}+\mathrm{Fe}_{3} \mathrm{O}_{4}\right)$ system for $\mathrm{H}_{2}$ production using concentrated solar energy," Solid State Ionics, vol. 172, no. 1-4, pp. 113-116, 2004.

[26] G. P. Joshi, N. S. Saxena, R. Mangal, A. Mishra, and T. P. Sharma, "Band gap determination of Ni-Zn ferrites," Bulletin of Materials Science, vol. 26, no. 4, pp. 387-389, 2003.

[27] M. Aronniemi, J. Lahtinen, and P. Hautojärvi, "Characterization of iron oxide thin films," Surface and Interface Analysis, vol. 36, no. 8, pp. 1004-1006, 2004.

[28] Y.-Q. Chu, Z.-W. Fu, and Q.-Z. Qin, "Cobalt ferrite thin films as anode material for lithium ion batteries," Electrochimica Acta, vol. 49, no. 27, pp. 4915-4921, 2004.

[29] T. Sano, M. Kojima, N. Hasegawa, M. Tsuji, and Y. Tamaura, "Thermochemical water-splitting by a carbon-bearing $\mathrm{Ni}$ (II) ferrite at $300^{\circ}$ c," International Journal of Hydrogen Energy, vol. 21, no. 9, pp. 781-787, 1996.

[30] T. Tsurumi, T. Suzuki, M. Yamane, and M. Daimon, "Fabrication of barium titanate/strontium titanate artificial superlattice by atomic layer epitaxy," Japanese Journal of Applied Physics, Part 1, vol. 33, no. 9B, pp. 5192-5195, 1994.

[31] C. C. Agrafiotis, C. Pagkoura, S. Lorentzou, M. Kostoglou, and A. G. Konstandopoulos, "Hydrogen production in solar reactors," Catalysis Today, vol. 127, no. 1-4, pp. 265-277, 2007.

[32] R. S. Gaikwad, S. Y. Chae, R. S. Mane, Cai-Gangri, S. H. Han, and O. S. Joo, "Large area $\left(9 \times 9 \mathrm{~cm}^{2}\right)$ electrostatically sprayed nanocrystalline zincite thin films for hydrogen production application," International Journal of Hydrogen Energy, vol. 35, no. 13, pp. 6549-6553, 2010. 


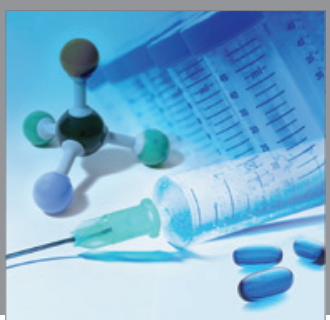

International Journal of

Medicinal Chemistry

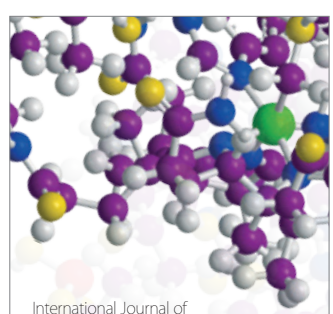

Carbohydrate Chemistry

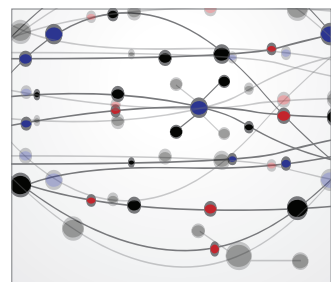

The Scientific World Journal
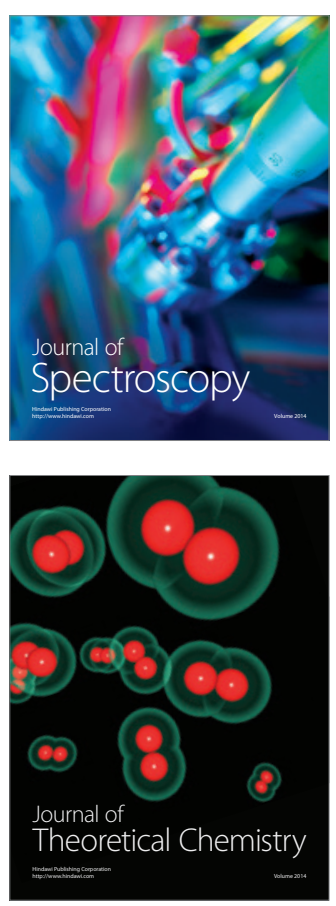
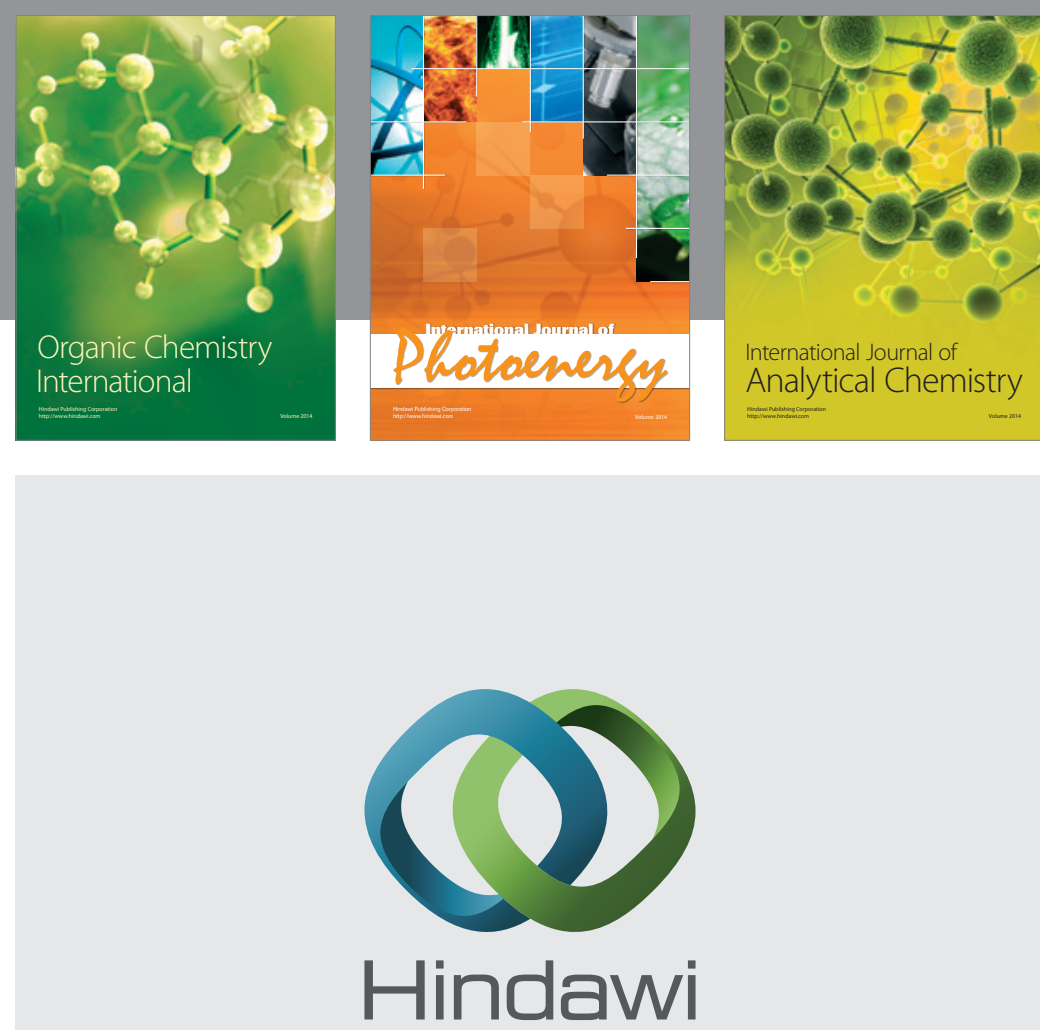

Submit your manuscripts at

http://www.hindawi.com
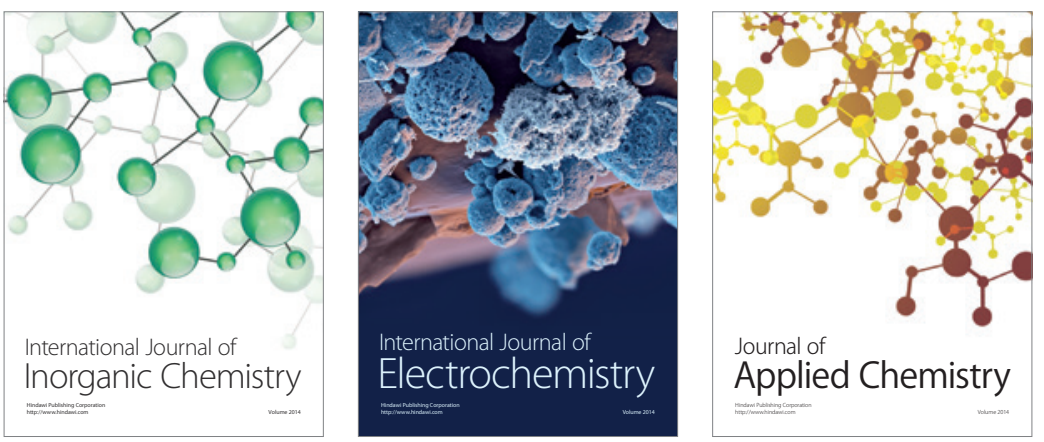

Journal of

Applied Chemistry
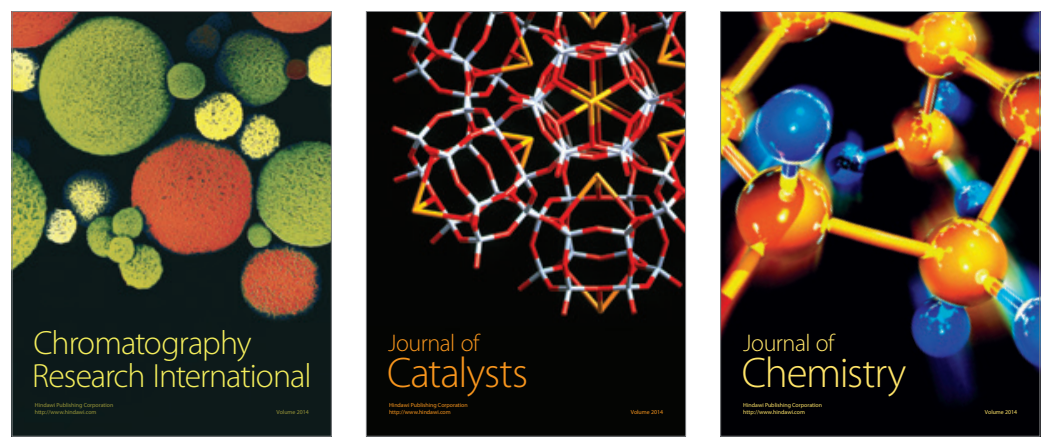
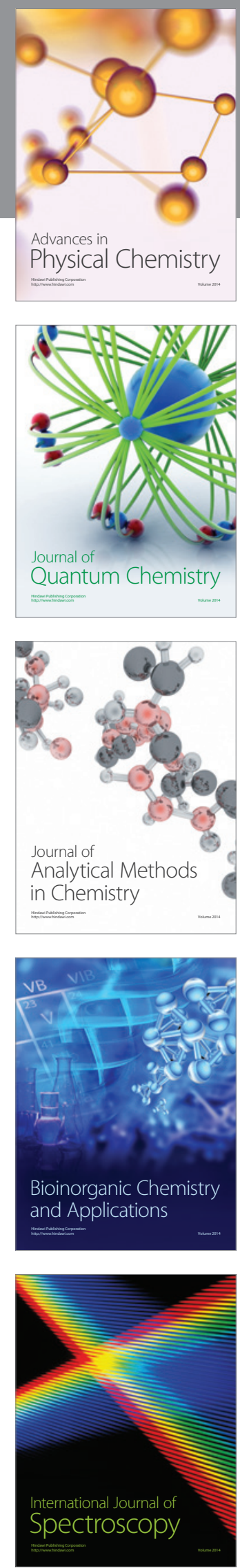